\title{
Congenital physiologically corrected transposition with hypertrophic obstructive cardiomyopathy
}

\author{
Michael Honey and Ronald G. Gold ${ }^{2}$ \\ From the Department of Cardiology, Brompton Hospital, London S.W.3
}

Two cases of congenital physiologically corrected transposition are reported in which there was associated hypertrophic obstructive cardiomyopathy, in one case affecting mainly the left-sided (morphological right) ventricle, and in the other the right-sided (morphological left) ventricle. In the former there was dextrorotation with mesocardia.

Corrected transposition is commonly associated with other congenital abnormalities of the heart, notably ventricular septal defect, pulmonary stenosis, incompetence, or an Ebstein type of anomaly of the tricuspid leftsided atrioventricular valve, and all degrees of heart block (Anderson, Lillehei, and Lester, 1957; Schiebler et al., 1961; Honey, 1963; Van Praagh, Vlad, and Keith, 1967). Pulmonary stenosis is usually valvar; the right-sided pulmonary (morphological left) ventricle has no infundibulum, and when subvalvar stenosis occurs it resembles subvalvar aortic stenosis in the otherwise normal heart (Anderson et al., 1957; Payne, Ellis, and Hunt, I96I ; Schiebler et al., I96I ; Van Mierop et al., I96I ; Caulfield, Bostock, and Perloff, I967). Valvar or infundibular aortic stenosis has not been described, but Todd, Anderson, and Edwards (1965) reported an infant with corrected transposition and an anomalous muscle bundle in the left-sided systemic (morphological right) ventricle, resembling that which may cause outflow tract obstruction in the right ventricle of hearts with normal chamber localization.

Hypertrophic obstructive cardiomyopathy (Cohen et al., 1964) (idiopathic hypertrophic subaortic stenosis: Braunwald et al., 1964) is usually an isolated abnormality, either familial or sporadic, which may be congenital or acquired. In only a small proportion of cases is it associated with any other type of congenital cardiovascular abnormality; this is usually

Received 27 July 1970.

1 Present address: Shotley Bridge General Hospital, Shotley Bridge, Consett, Co. Durham. one normally resulting in left ventricular hypertrophy (for example, coarctation of the aorta, ventricular septal defect, valvar or discrete subvalvar aortic stenosis), but the condition has been observed in association with secundum atrial septal defect (King, Vogel, and Blount, 1965; Somerville and McDonald, I968; Honey, unpublished case), and situs inversus (King et al., 1965). Hypertrophic obstructive cardiomyopathy commonly affects the left ventricle alone, but in a proportion of cases there is evidence also of right ventricular involvement (Wigle, Heimbecker, and Gunton, 1962; Braunwald et al., 1964; Cohen et al., 1964; Taylor, Bernstein, and Jose, 1964; King et al., 1965; Lockhart et al., 1966; Falcone, Moore, and Lambert, 1967; Frank and Braunwald, I968), with outflow tract obstruction or a localized apical high pressure zone. Falcone et al. (1967) reported a case in which the only demonstrable abnormality was in the right ventricle, and Frank and Braunwald (1968) have recorded two patients with outflow tract gradients on the right side only.

In this report we describe two cases showing the hitherto unreported association of congenital physiologically corrected transposition with hypertrophic obstructive cardiomyopathy.

\section{Case reports}

Case I A 31-year-old Indian man complained of left-sided chest pain not constantly related to effort, but was otherwise symptomless. There was no family history of heart disease. A routine chest radiograph showed an abnormal heart shadow, and he was referred for assessment. 


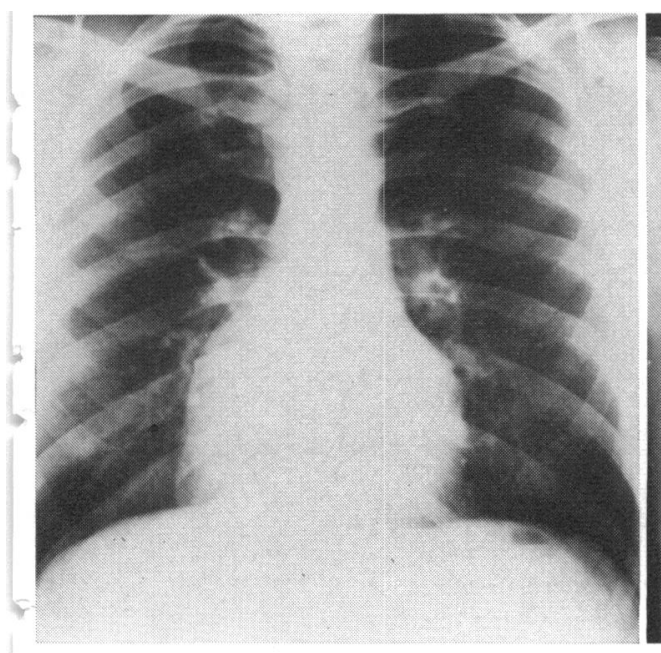

A

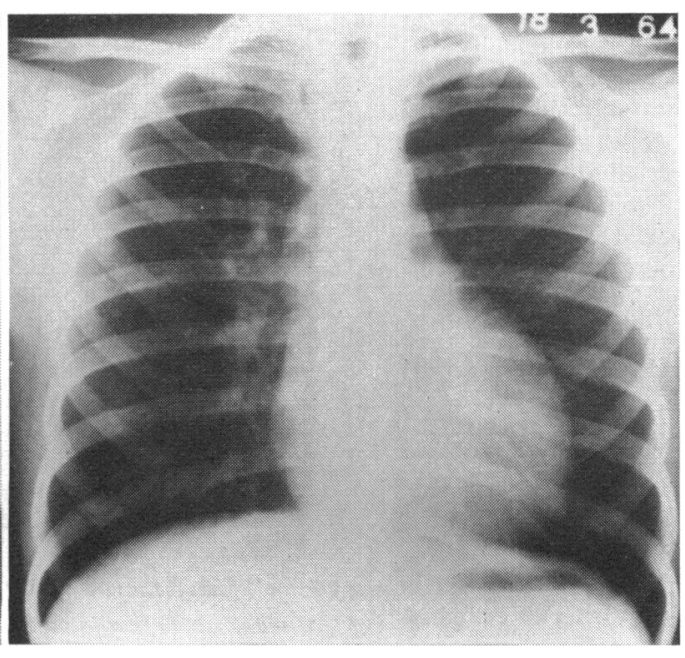

B

FIG. I Chest radiographs. A, Case I. B, Case 2.

On examination his appearance was healthy. -The brachial arterial pulse had a sharp upstroke. The blood pressure was $100 / 60 \mathrm{~mm}$. $\mathrm{Hg}$. There was a dominant $a$ wave in the jugular venous pulse. The heart was not clinically enlarged; a quiet (grade 2/6) systolic ejection murmur was audible to the left of the sternum. The second sound was variably split, sometimes paradoxical, and sometimes normal but close; the aortic component was accentuated and palpable. Other systems were normal.

- The chest radiograph (Fig. IA) showed the heart to be displaced to the right; the aortic arch was left-sided and the stomach gas-bubble was on the left. The pulmonary vascular pattern was normal.
The electrocardiogram (Fig. 2A) showed normal sinus rhythm, with mean frontal $P$ vector $+75^{\circ}$ and mean frontal $Q R S$ vector $+10^{\circ}$. There were voltage changes of left ventricular hypertrophy, with ST depression and inverted $T$ waves in leads I, II, aVL, and V4-V6 (mean frontal T vector $\left.+165^{\circ}\right)$. There were no $Q$ waves in any lead.

Cardiac catheterization (Table I) The catheter was passed from a right antecubital vein by way of a right-sided superior vena cava into a normally situated right atrium, thence through the right atrioventricular valve and a right-sided ventricle to the pulmonary trunk, all situated abnormally far to the right. A Dacron Gensini catheter, intro-

2FIG. 2 Electrocardiograms. A, Case I. B, Case 2.
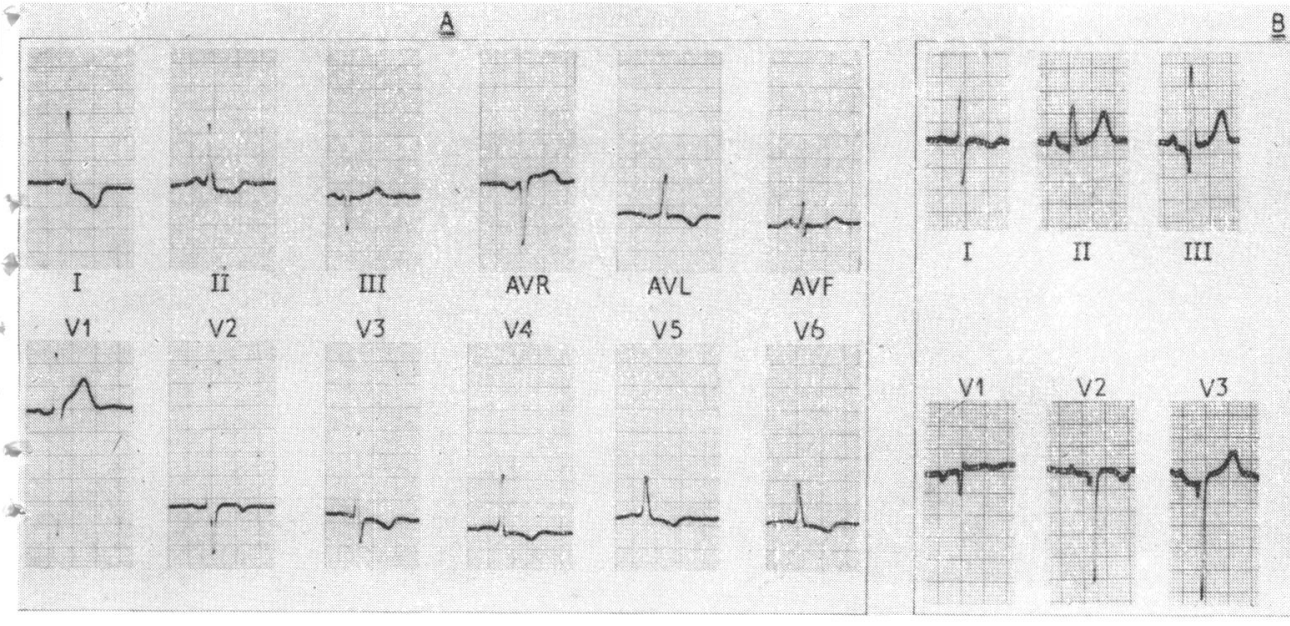

$\underline{B}$

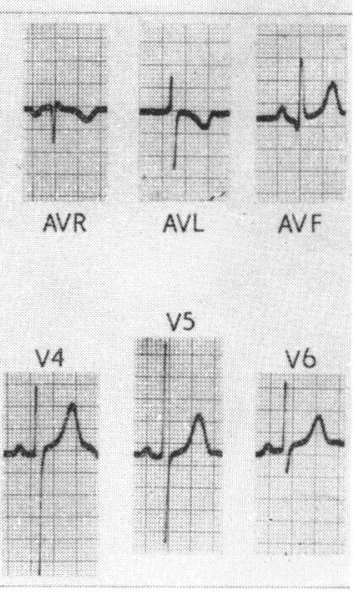


duced percutaneously into the right femoral artery by the Seldinger method, was advanced to the ascending aorta, which was situated to the left of the pulmonary trunk and into the left-sided systemic ventricle. There was a small systolic gradient in the outflow tract of the pulmonary ventricle. Oxygen analyses showed no left-to-right shunt; a low systemic arterial saturation was probably due to oversedation. There was no resting gradient between the left-sided ventricle and the brachial artery, but after slow injection of isoprenaline $(6 \mu \mathrm{g}$.) the maximum gradient was $75 \mathrm{~mm}$. Hg (Fig. 3).

A biplane angiocardiogram (Fig. 4), with injection of 85 per cent Hypaque into the right-sided ventricle, showed the characteristic appearances of corrected transposition. The right-sided ventricle had the morphological appearances of a left ventricle, with smooth wall and no crista supraventricularis or infundibulum. The pulmonary valve was directly related to the right atrioventricular valve, and the pulmonary trunk was situated posteriorly and in the midline. The leftsided ventricle showed a crista, and the aortic valve was anterior and superior to the pulmonary valve. The aorta ascended directly upwards, parallel and to the left of the pulmonary trunk. In addition there was dextrorotation of the apex of the heart, so that the ventricles lay side by side and the major part of the ventricular mass was to the right of the midline. Cine-angiocardiography, in the posteroanterior view, with injection of 85 per cent Hypaque into the left-sided ventricle, showed slight regurgitation through the left atrioventricular valve. The ventricular wall was thick, and in systole there was encroachment on the outflow tract from both sides. Injection of opaque medium into the left subclavian vein showed no left superior vena cava.

Comment This patient has l-transposition, with normal visceroatrial situs, bulboventricular in-

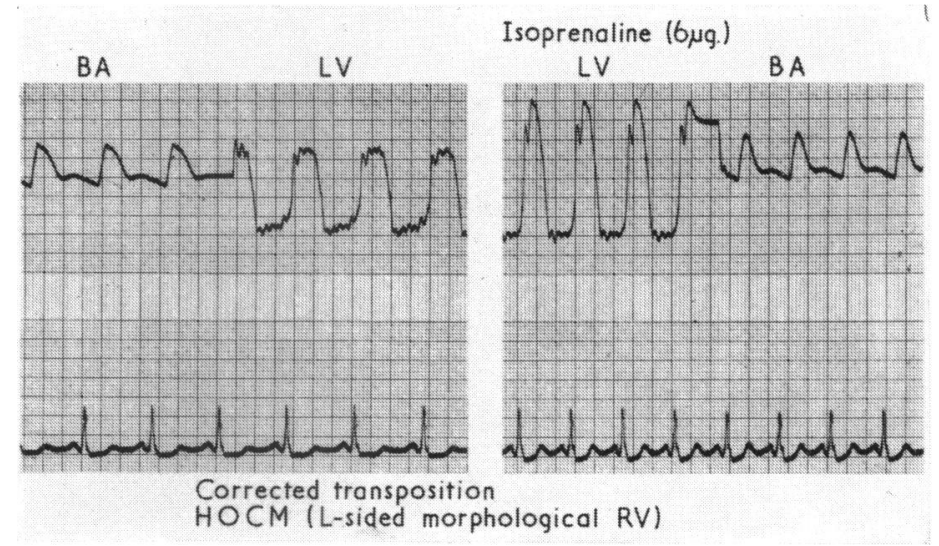

FIG. 3 Case I: Immediately successive pressure records from brachial artery $(B A)$ and left-sided systemic ventricle $(L V)$. Left, before isoprenaline: Right, after isoprenaline (6 $\mu \mathrm{g}$.).

version (1-loop), and also dextrorotation of the heart. There is hypertrophic obstructive cardiomyopathy affecting the left-sided (morphological right) ventricle. Though there was no gradient at rest, one was readily provoked by injection of isoprenaline (Braunwald and Ebert, 1962), and the electrocardiogram showed evidence of hypertrophy of the left-sided ventricle with ST segment and $T$ wave abnormalities. The diagnosis of hypertrophic obstructive cardiomyopathy was made on clinical grounds before investigation. The abnormal position of the heart was recognized, but there were no clinical, radiological, or electrocardiographic clues to the diagnosis of corrected transposition, except for accentuation

FIG. 4 Case I: Angiocardiograms. Injection (85\% Hypaque) into right-sided pulmonary ventricle. $A$, early anteroposterior film showing rightward displacement of right-sided ventricle and midline position of pulmonary trunk. $B$, early lateral film showing posteriorly placed pulmonary trunk. $C$, late anteroposterior film, and $D$, late lateral film showing laevotransposition of aorta.

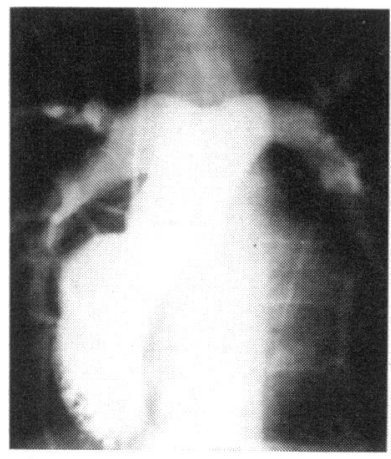

A

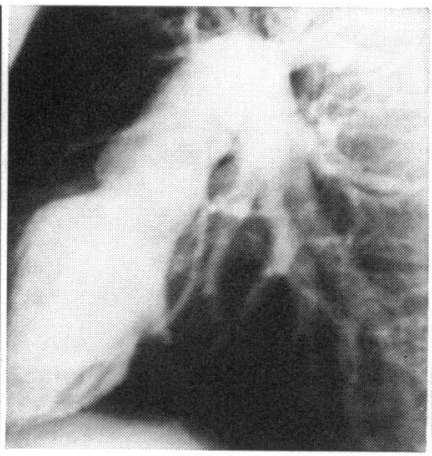

B

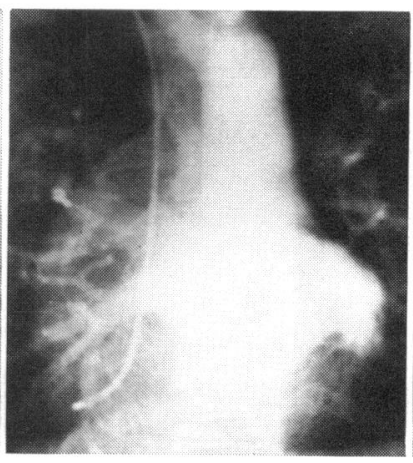

C

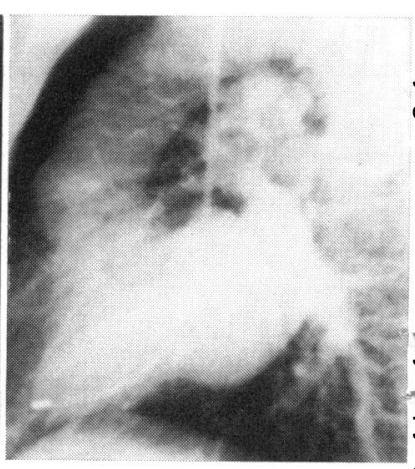

D 
of the aortic closure sound resulting from the anterior position of the valve (Honey, 1963). No treatment was advised.

1 Case 2 An 8-year-old girl was admitted for investigation after the discovery of a heart murmur six months previously on examination before operation for congenital strabismus. She had no symptoms. The mother's pregnancy had been normal, and there was no family history of heart - disease. There was no relevant past medical history.

On examination, she was a well-built child. The

- arterial pulse was normal and regular, and the blood pressure was $135 / 90 \mathrm{~mm}$. Hg. The jugular venous pressure was not raised and the venous pulse was normal. The heart was not clinically enlarged. There was a long loud (grade 4/6) systolic ejection murmur, maximal in the second

- and third intercostal spaces at the left border of the sternum. The murmur extended beyond - aortic closure up to the delayed, quiet pulmonary component of the second sound. There was a loud third heart sound, but no ejection sound. Other systems were normal.

The chest radiograph (Fig. IB) showed a globular heart with a cardiothoracic ratio of 47

- per cent and a prominent bulge of the upper portion of the left heart border. The aortic knuckle

- was not visible. The pulmonary vascular pattern was normal.

The electrocardiogram (Fig. 2B) showed sinus arrhythmia. The mean frontal $Q R S$ vector was $+90^{\circ}$, and the $\mathrm{T}$ waves were inverted in lead I (mean frontal $\mathrm{T}$ vector $+100^{\circ}$ ). There were - abnormal $\mathrm{Q}$ waves in $\mathrm{VI}_{\mathrm{I}}-\mathrm{V}_{3}$, but no $\mathrm{Q}$ waves in $\mathrm{V}_{4}$-V6.

Cardiac catheterization (Table 2) The catheter was passed from a right antecubital vein to the right atrium and thence to a high pressure ventricle; great difficulty was experienced in entering the pulmonary trunk from the ventricle, but this was eventually accomplished with the catheter taking a very medial course (Honey,

7 1963). There was a $100 \mathrm{~mm}$. Hg gradient across the outflow tract, but none at valve level. Propranolol

- (5 mg.) injected slowly produced a greater fall in pressure in the right-sided ventricle than in the brachial artery, but unfortunately it was not possible to re-enter the pulmonary artery at this stage.

A biplane angiocardiogram (Fig. 5), with injection of 75 per cent Triosil into the rightsided ventricle, showed that this had the mor- phology of a left ventricle, with gross hypertrophy of its wall and of the interventricular

- septum. The outflow tract was almost completely obstructed by very large hypertrophic muscle masses, leaving only a narrow channel for passage of the contrast medium. The pulmonary valve

- was large but otherwise normal. The pulmonary trunk was greatly enlarged and situated posteriorly

- and medially. The left-sided ventricle was small and had the morphology of a right ventricle. The ascending aorta was small, anterior, and to the
TABLE I Haemodynamic data on Case I

\begin{tabular}{|c|c|c|c|c|}
\hline Site & $\begin{array}{l}\text { Blood } \mathrm{O}_{2} \\
\text { content } \\
\text { (vol. } \% \text { ) }\end{array}$ & $\begin{array}{l}\text { Blood } \mathrm{O}_{2} \\
\text { saturation } \\
(\%)\end{array}$ & $\begin{array}{l}\text { Pressure } \\
(\mathrm{mm} . \mathrm{Hg})\end{array}$ & $\begin{array}{l}\text { Pressures* } \\
\text { after } \\
\text { isoprenaline } \\
(\mathrm{mm} . \mathrm{Hg})\end{array}$ \\
\hline $\begin{array}{l}\text { Superior vena cava } \\
\text { Inferior vena cava } \\
\text { Right atrium } \\
\text { Pulmonary ventricle } \\
\text { Pulmonary artery } \\
\text { Pulmonary artery wedge } \\
\text { Aorta } \\
\text { Systemic ventricle }\end{array}$ & $\begin{array}{l}12 \cdot 7 \\
15 \cdot 3 \\
12 \cdot 7-13 \cdot 8 \\
12 \cdot 7-13 \cdot 0 \\
13 \cdot 0 \\
17 \cdot 7\end{array}$ & $\begin{array}{l}65 \\
79 \\
65-71 \\
65-67 \\
67\end{array}$ & $\begin{array}{l}a=7 \text { mean } 0 \\
35 / 6 \\
26 / 9 \\
v=11 \text { mean } 9 \\
95 / 68 \\
98 / 7\end{array}$ & \\
\hline $\begin{array}{l}\text { Systemic ventriclef } \\
\text { Brachial artery } \dagger\end{array}$ & & & $\begin{array}{l}112 / 20 \\
115 / 65\end{array}$ & $\begin{array}{l}190 / 7 \\
115 / 62\end{array}$ \\
\hline
\end{tabular}

Oxygen uptake $231 \mathrm{ml} . / \mathrm{min}$.

Cardiac output $4.91 . / \mathrm{min}$. $\left(2.51 . / \mathrm{min} . / \mathrm{m} .{ }^{2}\right)$.

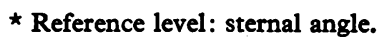

† Simultaneous pressures after angiocardiography, before and after isoprenaline.

left. Cine-angiocardiography, with injection into the same ventricle, showed severe systolic shutdown of the hypertrophic outflow tract obstruction.

Surgical treatment was not advised. Four years later the child was seen after a syncopal episode, and was found to have developed heart block. Dropped beats, 2:I atrioventricular block, and complete heart block were seen at different times (Fig. 6). On exercise and after isoprenaline the ventricular rate increased to $66 / \mathrm{min}$. Treatment was continued with sustained-action isoprenaline (Saventrine).

TABLE 2 Haemodynamic data on Case 2

\begin{tabular}{|c|c|c|c|c|}
\hline Site & $\begin{array}{l}\text { Blood } \mathrm{O}_{2} \\
\text { content } \\
\text { (vol. \%) }\end{array}$ & $\begin{array}{l}\text { Blood } \mathrm{O}_{2} \\
\text { saturation } \\
(\%)\end{array}$ & $\begin{array}{l}\text { Pressure } \\
(\mathrm{mm} . \mathrm{Hg})\end{array}$ & $\begin{array}{l}\text { Pressures } \\
\text { after } \\
\text { propranolol } \\
\text { (mm. } \mathrm{Hg})\end{array}$ \\
\hline $\begin{array}{l}\text { Superior vena cava } \\
\text { Inferior vena cava } \\
\text { Right atrium } \\
\text { Pulmonary ventricle } \\
\text { Pulmonary ventricle (outflow) } \\
\text { Pulmonary artery } \\
\text { Pulmonary artery wedge } \\
\text { Brachial artery }\end{array}$ & $\begin{array}{l}12 \cdot 0 \\
13 \cdot 2 \\
12 \cdot 2 \\
11 \cdot 8 \\
12 \cdot 0 \\
11 \cdot 8-12 \cdot 0 \\
18 \cdot 0\end{array}$ & $\begin{array}{l}64 \\
70 \\
65 \\
63 \\
64 \\
63-64 \\
96\end{array}$ & $\begin{array}{l}a=3 \text { mean } 0 \\
115 / 10 \\
15 / 0 \\
18 / 10 \text { mean } 12 \\
v=8 \text { mean } 5\end{array}$ & \\
\hline $\begin{array}{l}\text { Pulmonary ventriclet } \\
\text { Brachial artery } t\end{array}$ & & & $\begin{array}{l}100 / 5 \\
95 / 60\end{array}$ & $\begin{array}{l}75 / 5 \\
85 / 45\end{array}$ \\
\hline
\end{tabular}

Oxygen uptake (assumed basal) $150 \mathrm{ml} . / \mathrm{min}$. Cardiac output $2 \cdot 4$ 1./min.

* Reference level: sternal angle.

† Simultaneous pressures before and after propranolol. 


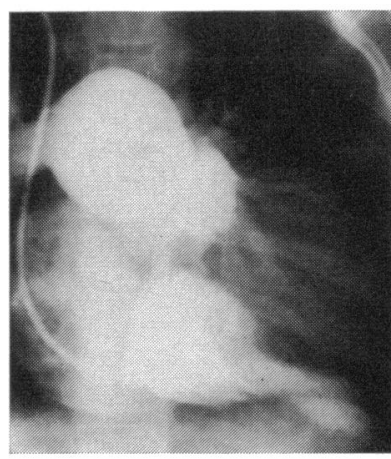

A

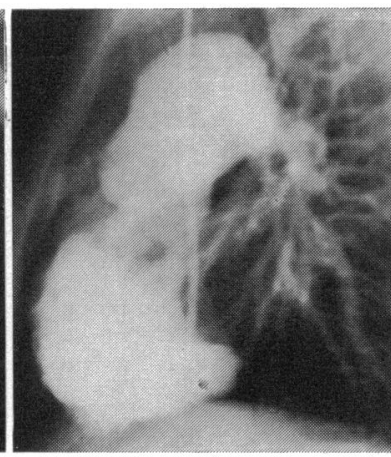

B

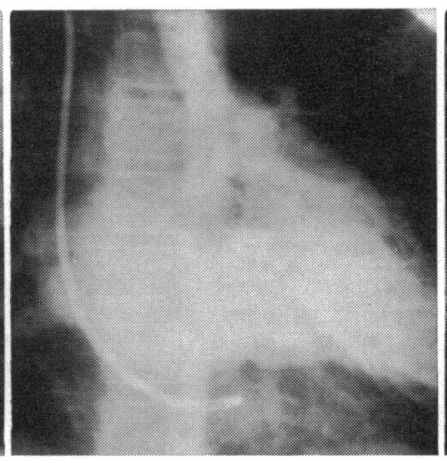

C

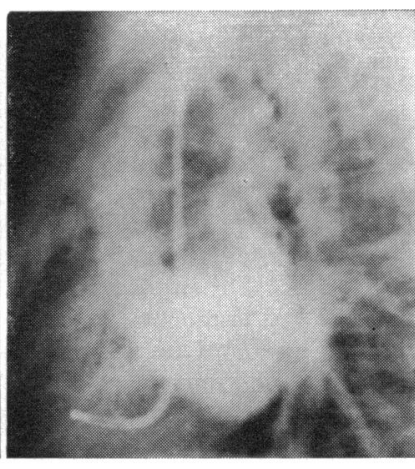

$\mathrm{D}$

FIG. 5 Case 2: Angiocardiograms. Injection ( $75 \%$ Triosil) into right-sided ventricle. $A$, early anteroposterior film, showing gross hypertrophic subvalvar obstruction. $B$, early lateral film. $C$, late anteroposterior film. D, lateral film, showing laevotransposition.

Comment This patient has l-transposition, with normal visceroatrial situs and bulboventricular inversion (1-loop), and a hypertrophic obstructive cardiomyopathy affecting the right-sided left ventricle. The clinical findings suggested pulmonary stenosis, probably subvalvar, but the electrocardiogram showed none of the usual signs of right ventricular hypertrophy. The absence of a typical right ventricular hypertrophy pattern on the electrocardiogram in patients with corrected transposition and hypertrophy of the right-sided ventricle has been noted previously (Gibbons et al., 1956; Schiebler et al., 196r; Honey, 1963). The abnormal $T$ vector may reflect hypertrophy of the left-sided ventricle. Though the systolic pressures in the right-sided ventricle and the systemic artery were initially the same, they were separated by propranolol and there was no evidence of an associated ventricular septal defect. Heart block later appeared.

\section{Discussion}

In our two cases hypertrophic obstructive cardiomyopathy is associated with corrected transposition. In both cases the corrected transposition is of the usual type, with 1transposition, bulboventricular inversion (1loop), and normal visceroatrial situs (Van Praagh et al., 1967). In Case I obstruction in the outflow tract of the left-sided (morphological right) ventricle was revealed by isoprenaline injection. There was also a small gradient in the right-sided (morphological left) ventricle. In addition the heart is shifted rightwards to occupy a mid-position in the thoracic cavity. The location of the major obstructive lesion in the right ventricle is very unusual, and may in this case be related to the fact that this is the systemic ventricle. In Case 2 the outflow tract obstruction involved the right-sided (morphological left) ventricle. In neither case was there any other associated congenital lesion, nor any clinically recognizable lesion of the left atrioventricular valve. Case 2 later developed heart block. In neither case was a family history of heart disease obtained.

We wish to thank Dr. R. V. Gibson for his permission to publish Case 2.

FIG. 6 Case 2: Electrocardiograms. $A$, dropped beats (lead II). B, 2:I AV block (lead I). C, complete heart block, with isoprenaline infusion (lead I). D, complete heart block during exercise (lead II).

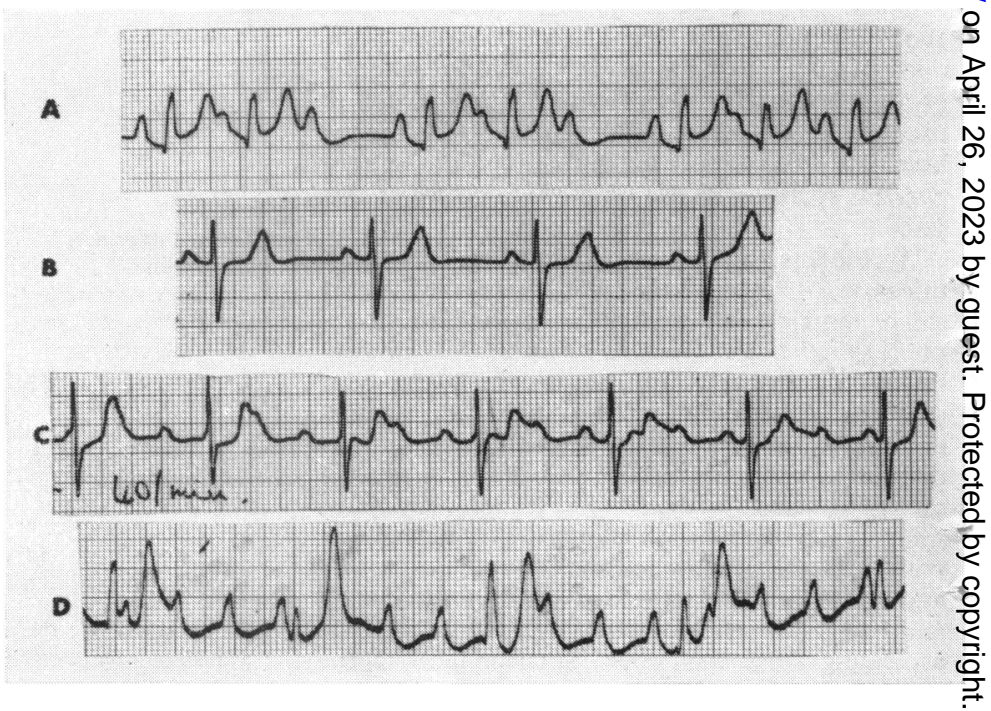




\section{References}

Anderson, R. C., Lillehei, C. W., and Lester, R. G. (1957). Corrected transposition of the great vessels of the heart: a review of 17 cases. Pediatrics, 20, 626.

Braunwald, E., and Ebert, P. A. (1962). Hemodynamic alterations in idiopathic hypertrophic subaortic stenosis induced by sympathomimetic drugs. American fournal of Cardiology, ro, 489.

, Lambrew, C. T., Rockoff, S. D., Ross, J., and Morrow, A. G. (1964). Idiopathic hypertrophic subaortic stenosis: I. A description of the disease based upon an analysis of 64 patients. Circulation, 29-30, Suppl. IV, 3.

Caulfield, W. H., Bostock, B., and Perloff, J. K. (1967). Corrected transposition of the great vessels with isolated pulmonic stenosis: the paradox of pulmonic stenosis with physical signs of pulmonary hypertension. American fournal of Cardiology, 19, 285.

Cohen, J., Effat, H., Goodwin, J. F., Oakley, C. M., and Steiner, R. E. (1964). Hypertrophic obstructive cardiomyopathy. British Heart fournal, 26, I6.

Falcone, D. M., Moore, D., and Lambert, E. C. (1967). Idiopathic hypertrophic cardiomyopathy involving the right ventricle. American fournal of Cardiology, 19, 735.

Frank, S., and Braunwald, E. (1968). Idiopathic hypertrophic subaortic stenosis: clinical analysis of 126 patients with emphasis on the natural history. Circulation, 37, 759.

- Gibbons, J. E., Donnelly, G. L., Harris, J. S., and Orgain, E. S. (1956). Corrected transposition of the great vessels with pulmonary stenosis. Circulation, 14, 94 I.

Honey, M. (1963). The diagnosis of corrected transposition of the great vessels. British Heart fournal, 25, 313.

King, S. M., Vogel, J. H. K., and Blount, S. G. (1965). Idiopathic muscular subvalvular aortic stenosis with associated congenital cardiovascular lesions. American fournal of Cardiology, 15, 837.
Lockhart, A., Charpentier, A., Bourdarias, J. P., Ben Ismail, M., Ourbak, P., and Scebat, L. (I966). Right ventricular involvement in obstructive cardiomyopathies: haemodynamic studies in 13 cases. British Heart fournal, 28, 122.

Payne, W. S., Ellis, F. H., and Hunt, J. C. (196I). Congenital corrected transposition of the great vessels with situs inversus and dextrocardia: report of surgical repair of associated defects in a patient with pulmonary stenosis, interatrial communication and persistent 'left' superior vena cava. American fournal of Cardiology, 8, 288.

Schiebler, G. L., Edwards, J. E., Burchell, H. B., DuShane, J. W., Ongley, P. A., and Wood, E. H. (I96I). Congenital corrected transposition of the great vessels: a study of 33 cases. Pediatrics, 27, 85I.

Somerville, J., and McDonald, L. (1968). Congenital anomalies in the heart with hypertrophic cardiomyopathy. British Heart fournal, 30, 713.

Taylor, R. R., Bernstein, L., and Jose, A. D. (1964). Obstructive phenomena in ventricular hypertrophy. British Heart fournal, 26, 193.

Todd, D. B., Anderson, R. C., and Edwards, J. E. (1965). Inverted malformations in corrected transposition of the great vessels. Circulation, 32, 298.

Van Mierop, L. H. S., Alley, R. D., Kausel, H. W., and Stranahan, A. (I96I). Ebstein's malformation of the left atrioventricular valve in corrected transposition, with subpulmonary stenosis and ventricular septal defect. American fournal of Cardiology, 8, 270.

Van Praagh, R., Vlad, P., and Keith, J. D. (1967). Complete transposition of the great arteries. In Heart Disease in Infancy and Childhood, 2nd ed., pp. 682-744. Ed. by J. D. Keith, R. D. Rowe, and P. Vlad. Macmillan, New York.

Wigle, E. D., Heimbecker, R. O., and Gunton, R. W. (I962). Idiopathic ventricular septal hypertrophy causing muscular subaortic stenosis. Circulation, 26, 325 . 